\title{
SUBCORTICOTOMIA DO LOBO ORBITÁRIO E DISTÚRBIOS INSTINTIVOS
}

\author{
Spartaco Vizzotto * \\ IsAías MELSOHN * \\ Afonso SETte JUNioR *
}

\author{
Aloysio Mattos Pimenta ** \\ Paulo Mangabeira Albernaz $\mathrm{F}^{\circ * *}$ \\ ROBERTO TOMCHINSKY *
}

LuIz J. A. FIORE*

A análise dos resultados das intervenções cirúrgicas no cérebro de doentes mentais leva à conviç̧ão de que êste processo terapêutico tem o seu lugar definitivamente assegurado em Psiquiatria, especialmente em relação às psicoses crônicas, incuráveis; nos casos de lesões cerebrais irreversíveis e de distúrbios do desenvolvimento de caráter definitivo nenhuma outra possibilidade terapêutica existe, na tentativa de promover melhor harmonia funcional entre as diferentes regiōes do encéfalo, do que a retirada das partes lesadas ou a interrupção parcial ou total de conexões com as zonas não atingidas.

A nosso ver, o descrédito que em certos meios científicos é votado à psicocirurgia advém dos êrros metodológicos que tem prevalecido na maioria das pesquisas realizadas neste campo:

a) Primeiramente encontramos as teorias de base puramente especulativa que pretendem negar a especialização das áreas cerebrais, argumentando em têrmos de quantidade, de massa do tecido cerebral. Os fracassos das terapêticas baseadas em tal orientação não puderam ser ocultados por muito tempo.

b) Talvez o elemento mais importante como responsável pelos maus resultados obtidos consista na interpretaçāo dos resultados das experiências de neurofisiologia em animais, pois não têm sido consideradas as diferenças anátomo-funcionais entre o cérebro humano e dos animais de laboratório; além disto as ablaçōes de áreas cerebrais em animais sāo operações grosseiras que podem conduzir a falsas conclusōes. É o que tem sucedido, por exemplo, em relação à área 13, na parte posterior do lobo orbitário. Em 1943 Ruch e Shenkin "descobriram" que, em macacos, a ablação bilateral da circunvolução orbitária posterior determinava marcada hipermotilidade; a partir dessa verificacão, Dax e Radley-Smith ${ }^{3}$ preconizaram a ablação ou secção seletiva do córtex orbitário ou de suas projeçōes em casos de "depressão passiva" e estupor catatônico. No entanto, Turner ${ }^{13}$ confirmou a impressão anterior de Davis e col.2 de que a ablação da área $13 \mathrm{em}$ macacos não é a responsável por hipercinesias que ocorreriam por conta da isquemia da cabeça do núcleo caudado, provocada pela referida ablação. Scoville ${ }^{8}$, que também tem seguido a orientação

Trabalho realizado no Hospital de Juqueri, apresentado ao $\mathrm{V}$ Congresso Brasileiro de Psiquiatria, Neurologia e Higiene Mental (julho de 1958, Salvador - Bahia).

* Médicos do Hospital de Juquerl; ** Neurocirurgiōes da Escola Paulista de Medicina (Prof. Paulino Longo). 
de Dax e que foi o idealizador da técnica que empregamos, acabou por verificar que, em sua intervenção, a área 13 não era prảticamente atingida, o que invalidou todo o raciocínio anterior. De outro lado, os resultados obtidos na prática psicocirúrgica, de modo algum confirmaram tais assertivas hipotéticas. Podemos exprimir êste êrro metodológico dizendo que os dados que a neurofisiologla nos faculta nas pesquisas em animais devem ser correlacionados com os demais conhecimentos advindos de outros setores de pesquisas e, principalmente, devem ser aferidos mediante método anátomo-clínico.

c) Outra causa de desorientação tem sido a deficiente análise psicopatológica dos pacientes, eivada de conceitos abstratos sem correspondēncia na realidade objetiva. De fato, o padrāo das observaçōes tem decaido a partir de Bleuler que, influenciado pela corrente psicanalítica, ressaltou o aspecto dinâmico inconsciente da psicopatologia. A busca de ilusórios sintomas chamados essenciais, fundamentais ou primários que seriam "a chave mágica" para a compreensão de quadros psicopatológicos os mais complexos e variados, desiocou o psiquiatra da clinica para o isolamento da biblioteca, afastou-a do doente, tornando-o mais especulador que cientista. Constituem exceçôes Kleist ${ }^{4}$ e Aníbal Silveira "', cujos trabalhos não têm sido levados na devida conta ao serem indicadas intervencões psicocirúrgicas.

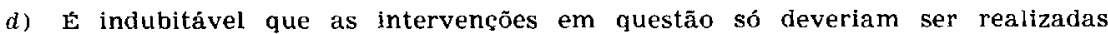
após vảrios anos de evolução da moléstia mental e depois de terem sido esgotados todos os recursos terapêuticos. Ademais, faz-se obrigatório um acurado estudo do caso e previsão dos sintomas deficitários pós-intervenção. Scovilles afirma que a subcorticotomia do lobo orbitário determina menos déficit psiquico que aplicações prolongadas de electrochoque. De há muito se conhecem as alteraçōes provocadas pela electrochoqueterapia no tecido nervoso, sob a forma de micro-hemorragias, e também os déficits acentuados no trabalho mental que se seguem a essa terapêutica; no entanto, ésses efeitos secundários tendem a desaparecer em poucos meses quando a freqüência das aplicações é pequena. Talvez Scoville queria se referir aos tratamentos de "aniquilamento" pelo electrochoque que consistem em aplicaçōes sucessivas durante vários dias consecutivos, a fim de manter os pacientes agitados em estado de inconsciência. De qualquer modo, os efeitos destrutivos da subcorticotomia sāo muito maiores.

A contribuição que apresentamos deriva da aplicação das idéias contidas em trabalho de Vizzotto e Mattos Pimenta ${ }^{11}$ que, baseados nas investigaçōes de Kleist e Aníbal Silveira, sugeriram a decorticação do lobo orbitário nos casos de distúrbios instintivos. O fundamento teórico desta indicação neurocirúrgica reside na psicofisiologia do lobo orbitário estabelecida por Kleist.

Em linhas gerais, a síndrome do lobo orbitário traduz-se por exaltação instintiva nas esferas sexual, nutritiva e impulsiva. Apresentam os pacientes liberaçōes de impulsos sexuais da mais variada espécie - atentados ao pudor, perversões, aumento da atividade genésica, ciūmes mórbidos, idéias prevalentes de fundo sexual - hiperatividade motora, hiperfagia. Trata-se de pacientes em continuas atitudes anti-sociais que, em geral, terminam os seus dias em hospícios ou cadeias. A leucotomia standard de Freeman, usada em alguns dêstes casos, determinou piora da conduta em virtude do déficit intelectual conseqüente à intervenção. Na Europa, especialmente nos países nórdicos, tem sido feita a castração dos pacientes, também com resultados precários. 


\section{OBSERVAC̄OES}

Caso 1 - G. D., ccm 47 anos de idade, branco, brasileiro, internado em setembro de 1951 (R.G. 36.031). Trata-se de paciente que havia apresentado atraso no desenvolvimento psicomotor, começando a andar e falar aos 3 anos de idade. Aos 7 anos passou a masturbar-se em excesso e, aos 15, tinha grande necessidade de práticas sexuais. Por vêzes manifestou agressividade em relação aos famlliares. Desde os 16 anos de idade apresenta crises convulsivas tipo grande mal.

Exame psiquico - Nivel mental da imbecilidade. Associação pobre de idéias, sempre em tôrno de tema sexual. Tendência a liberação de impulsos sexuais e agressivos. Os exames de rotina (neuro-ocular, liquiido cefalorraquidiano, pneumencefalografia nada de anormal revelaram). Moléstia fundamental: Disgenesia do sistema nervoso central estendendo-se provàvelmente ao lobo orbitário.

o paciente foi operado em 3-5-1952: subcorticotomia orbitária bilateral. Acompanhamos o paciente até 23-6-1953, periodo em que permaneceu em sua residència, tendo desaparecido inteiramente os impulsos sexuais anormais.

Caso 2 - A. J. S., com 18 anos de idade, branco, brasileiro, internado em abril de 1951 (R.G. 49.884). Trata-se de paciente com nivel mental da imbecilidade, que há algum tempo vem constituindo grave problema para a familia em virtude de práticas homossexuais pouco discretas, causando conflitos com os vizinhos. No hospital passava quase todo o tempo recluso, pois bastava dar-lhe liberdade e vinham denúncias de práticas homossexuais. Os exames paraclínicos de rotina nada revelaram de anormal.

Submetido à subcorticotomia orbitária à esquerda, em 22-3-1953. Acompanhamos êste paciente até junho de 1958. Nunca mais os pais tiveram conhecimento de práticas homossexuais por parte do paciente, cuja capacidade de trabalho melhorou, talvez por atitude mais perseverante e atenciosa. Sua agressividade se manifestava apenas quando provocado. Ulteriormente passou a ingerir bebidas alcoólicas em demasia, o que provàvelmente acentuou as desordens de comportamento, pois apresentava fenômenos de embriaguez patológica, sob forma de obnubilação da consciência.

Caso 3 - F. R., com 33 anos de idade, rumeno, branco, internado em outubro de 1952 (R.G. 54.672). Trata-se de paciente que desde o ano de 1947 vem apresentando quadro mental classificável como esquizofrenia hebefrēnica autista, com a particularidade de seus delírios, monólogos e conversaçōes girarem quase sempre em tôrno de tema sexual. Foi o paciente mais perigoso que passou pelo pavilhão nos últimos 10 anos, tendo praticado inúmeras e graves agressōes. Os exames neuroocular e do liquido cefalorraquidiano nada de anormal revelaram. o pneumencefalograma revelou atrofias corticais na região parietal esquerda em sua porção mais elevada, sendo o ventrículo esquerdo maior que o direito. o paciente fol leucotomizado (técnica de Freeman-Watts) em 2-5-1953 e em 30-5-1953, para seccionar, respectivamente, os quadrantes inferior e superior, não havendo qualquer modificação dos sintomas.

Em 5-9-1953 foi praticada a subcorticotomia orbitária à direita, com excelentes resultados, pois o paciente tornou-se extremamente dócil e tolerante a ponto de ser encarregado da portaria do pavilhão, atividade que gera constantes atritos e da qual se desempenhou muito bem. Nenhuma alteraçāo foi observada no aspecto sexual. Há 4 anos teve alta, retornando ao meio familiar, nunca mais tendo praticado agressões; a atividade delirante, no entanto, continuou girando em tôrno de temas sexuais.

CASo 4 - E. P. V. N., com 16 anos de idade, branco, brasileiro, internado em março de 1955 (R.G. 62.990). Este paciente tem longa história iniciada aos 6 anos, com atos agressivos e atentados sexuais, dos quais resultaram prisões e expulsōes 
de institutos correcionais. Era pederasta ativo, desrespeitando vizinhas, criadas e, inclusive, sua irmã. Depois dos 12 anos fugia frequientemente de casa, ficando 8 ou mais dias entre os marginais, quebrando objetos e vidracas. Colocado no Abrigo de Menores, evadiu-se pelo menos três vêzes. Foi internado e expullso de várias colônias para anormais. Internado em vários hospitais e submetido aos tratamentos de choque nenhuma modificação apresentou. Exames de rotina (liqüido cefalorraquidiano, pneumencefalografia, electrencefalografia) sem anormalidades. Diagnóstico: personalidade psicopática amoral e perversa.

Foi operado em fevereiro de 1956 (subcorticotomia orbitária à esquerda). Durante cêrca de 30 dias em que estêve com a familia após a intervenção, foi observada acentuada mudança nos hábitos: já nāo andava nu pela casa e fechava a porta do banheiro; não foram observadas práticas sexuais. Notou o pai, apenas, maior arrogância por parte do paciente. Certo dia, estando com um grupo de rapazes, empenhou-se em uma briga com outro bando; um seu companheiro, receloso de que o paciente fôsse atingido na cabeça, pois sabia que isto lhe poderia ser fatal em virtude da recente operação, passou-lhe uma faca com a qual o paciente acabou por assassinar outro menino. Desde então, passou cêrca de 8 meses no Hospital de Juqueri, onde não apresentou conduta sexual anormal, embora tenha tido vários atritos e brigas. A seguir ficou 6 meses na Colónia de Itapira onde executou tarefas que o obrigavam a viajar para as cidades vizinhas, integrando-se satisfatòriamente em suas funções. Há cêrca de um ano reside com os pais, só sendo observados atritos esporádicos; sua conduta sob o ponto de vista sexual continuava perfeitamente normal. No entanto, de 6 meses para cá, surgiram crises convulsivas. Na mesma ocasião deu-se ao hábito da maconha e de bebidas alcoólicas. Em estado de embriaguez tornava-se confuso, praticando atos desordenados e agressivos, Há um mês voltou ao hospital, onde sua conduta tem sído normal.

\section{COMENTARIOS}

Os resultados obtidos, embora em poucos casos, confirmam as idéias de Kleist sôbre a psicofisiologia do lobo orbitário. Inesperados foram o efeito da subcorticotomia feita à direita sôbre a agressividade (caso 3) e os efeitos da subcorticotomia feita à esquerda sôbre os fenômenos de exaltação sexual (casos 2 e 4). No caso 1, em que a operação foi bilateral, os dois setores, agressivo e sexual, foram modificados.

Nossos três primeiros pacientes não se prestam para observação dos efeitos secundários da subcorticotomia, por serem deficientes mentais. Quanto ao último, o estudo da conduta e a comparação dos testes de Rorschach não mostraram modificação no plano intelectual. Revisão da literatura psicocirúrgica, no entanto, permite afirmar que a subcorticotomia é o tipo de leucotomia que determina menos sintomas deficitários. Bonner e col.', comparando os efeitos deficitärios determinados por intervenções psicocirúrgicas de vários tipos, praticadas em pacientes normais do ponto de vista mental, para tratamento de quadros dolorosos, concluem que a subcorticotomia é a mais inócua. Scoville $8,9,10$ afirma que esta intervenção afeta pouco ou nada a personalidade, recomendando-a para tratamento das psiconeuroses. Certos autores referem passageira liberação de atividade sexual, - que não observamos em nossos operados. Rylander afirma que não observou sintomas de desinibição na maioria dos casos que operou, não verificando também, mediante emprêgo de bateria de testes, qualquer diminuição do rendimento intelectual. O único trabalho que encontramos em que 
foi feita uma observação correlacionada com nosso ponto de vista é o de Strom-Olsen e col.12, no qual foi registrada diminuição de tendências agressivas e melhora de comportamento em pacientes nos quais a subcorticotomia foi realizada bilateralmente. Strom-Olsen foi o primeiro a registrar resultados totalmente em desacôrdo com as experiências em macacos segundo as quais a ablação do lobo orbitário determina hipermotilidade (Ruch e Shenkin ${ }^{6}$ ).

\section{RESUMO}

Os autores apresentam quatro casos de pacientes operados pela técnica de Scoville (subcorticotomia do lobo orbitário), a saber: dois deficientes mentais com exaltação sexual, um esquizofrênico crônico com exaltação sexual e grande agressividade e um jovem de 16 anos com graves distúrbios de conduta, especialmente nos setores da agressividade e sexo.

A base teórica para tal indicação foram as idéias de Kleist e A. Silveira sôbre a psicofisiologia do lobo orbitário. Os resultados foram tão nítidos que autorizam a comunicação dêste trabalho, embora com escassa casuística. Houve normalização parcial da conduta nos 4 pacientes.

Inesperadamente, o efeito sôbre o setor sexual mostrou evidente correlação com a intervenção praticada à esquerda, ao passo que a subcorticotomia à direita influiu especialmente sôbre as atitudes agressivas.

\section{SUMMARY}

Treatment of instinctive disturbances with orbital undercutting

Four cases operated by the Scoville technique (orbital undercutting) are reported namely: two patients with mental deficiency and sexual exaltation, one with chronic schizophrenia and sexual exaltation and great agressivity, a boy sixteen years old presenting severe behaviour disturbances, specially on the sexual sphere, with agressivity. The theoretical basis for such an operation are based on Kleist's and Anibal Silveira's ideas upon the psychophysiology of the orbital lobe.

The end-results of the operation were satisfactory; there was a partial normalization of behaviour in the four patients. Unexpectadly the effect upon the sexual behaviour showed an evident correlation following the intervention on the left side, while the orbital undercutting on the right side has an effect specially concerning the agressive behaviour.

\section{REFERENCIAS}

1. BONNER, F.; COBB, S.; SWEET, W. H.; WHITE, J. C. - Frontal lobe surgery in treatment of pain with considerations of post-operative psychological changes. Psychosom. Med., 14:383-405, 1952. 2. DAVIS, H. W.; EAST, I. C.; TAIT, H. S.; 
JOHNSON, S. C.; ROGERS, W. B. - West Virginia lobotomy project. J.A.M.A., 156: 939-943, 1954. 3. DAX, E.; RADLEY-SMITH, E. J. - Prefrontal leucotomy. Digest Neurol. a. Psychiat., 16:533-550, 1948. 4. KLEIST, K. - Discussion des rapports sur l'anatomo-physiologie cérébrale à la lumière des lobotomies et topectomies. Comptes Rendus du Premier Congrès Mondial de Psychiatrie (Paris) 3:59-64, 1952. 5. LASHLEY, K. S. - Coalescence of Neurology and Physiology. Proc. Am. Philos. Soc., 84:461-470, 1941. 6. RUCH, T. C.; SHENKIN, H. A. - The relation of area 13 on orbital surface of frontal lobes to hyperactibility and hyperphagia in monkeys. J. Neurophysiol., $6: 349-360,1943$. 7. RYLANDER, G. - Relief of symptoms and personality changes after superior convexity and orbital undercutting. Anais $V$ Congresso Internacional de Neurologia (Lisboa) $2: 213-214,1953$. 8. SCOVILLE, W. B. a) Selective cortical undercuting as a means of modifying and studying frontal lobe function in man. J. Neurosurg., 6:65-74, 1949; $b$ ) Orbital undercutting in the treatment of psychoneurosis, depressions and senile emotional states. Dis. Nervous System, 15:324-334, 1954. 9. SCOVILLE, W. B.; DUNAMORE, R. H.; LIBERSON, W. T.; HENRI, C. E.; PEPE, A. - Observations on medial temporal lobotomy and uncotomy in the treatment of psychotic states; preliminary review of 19 operative cases compared with 60 frontal lobotomy and undercutting cases. Res. Publ. Ass. Nerv. Ment. Dis., 31:347-373, 1952. 10. SCOVILLE, W. B.; WILK, E. K.; PEPE, A. J. Selective cortical undercutting: Results in new method of fractional lobotomy. Am. J. Psychiat., 107:730-737, 1951. 11. SILVEIRA, A. - Discussion des rapports sur l'anatomo-physiologie cérébrale à la lumière des lọbotomies et topectomies. Comptes Rendus du Premier Congrès Mondial de Psychiatrie (Paris) 3:86-95, 1952. 12. STROMOLSEN, R.; NORTHFIELD, D. W. C. - Undercutting of orbital cortex in chronic neurotic and psychotic tension states. Lancet, 269:986-991, 1955. 13. TURNER, E. A. - The Future of Psychosurgery. Birmingham M. Rev., 18:85-103, 1953. 14. VIZZOTTO, S.; PIMENTA, A. M. - La physiopathologie du lobe orbitaire dans son rapport avec la leucotomie. Comptes Rendus du Premier Congrès de Psychiatrie (Paris) 3:148-156, 1952.

Hospital de Juqueri - Franco da Rocha - São Paulo, Brasil. 